\title{
CHARACTERISTICS OF NATURAL BEACHES
}

\author{
Willard N. Bascom \\ Research Engineer, University of California \\ Scripps Institution of Oceanography \\ La Jolla, California
}

The subject of beach characteristics is a complex one which is obviously worthy of book-length treatment. The object of this paper is to describe briefly the shapes which groups of beach-forming particles take and the mechanisms by which the forces of nature have so arranged them. Using these reactions as criteria, the coastal engineer who is confronted with the problem of replenishing beach materials or of altering some existing sand flow with a shoreline structure will be able to understand (and predict) the rapid readjustment of the particles to their new environment. There are, of course, no unnatural beaches; the implication is that artificielly created or nourished beaches and otherwise altered shorelines will respond in the same manner as those untouched beaches which were studied to assemble the information presented here.

The most important characteristic of a beach is its dynamic nature; beaches are restiess, ever-shifting groups of particles which respond with great sensitivity to small changes in the natural forces that are quite imperceptable to man. A concept of this ceaseless change which reflects the wave characteristics is absolutely esseritial to the understanding of beach problems.

The actual shifting of the beach materials takes place under water and since the human mind cannot very well remember and compare the previous position of the surface with some later position, 1t may appear that little or no change is taking place. However, where there are rigid structures, such as pilings, projecting thru the beach for sand-level comparisons or where detailed surveys indicate that material has moved, the total volume in transport may prove to be astonishing. For example, the daily accretion to the sand spit in Santa Barbara harbor in some seasons is of the order of 700 yards a day (Bascom 1951) or equivalent to a large truck dumping 10 yards of sand there three times an hour, 24 hours a day continuously. Even though the area is small, this rapid growth is discernable only over an extended period of time or by survey and plotting which ioreshortens the time scale. Other cases of longshore sand movement are rarely so conveniently measured but such magnitudes are probably not unusual.

The other principal motion of beach material is off-shore - - onshore which is represented by the migration of the materials from bar to

"Contributions from the Scripps Institution of Oceanography, New Serie8, No. 674" 
COASTAL ENGINEERING

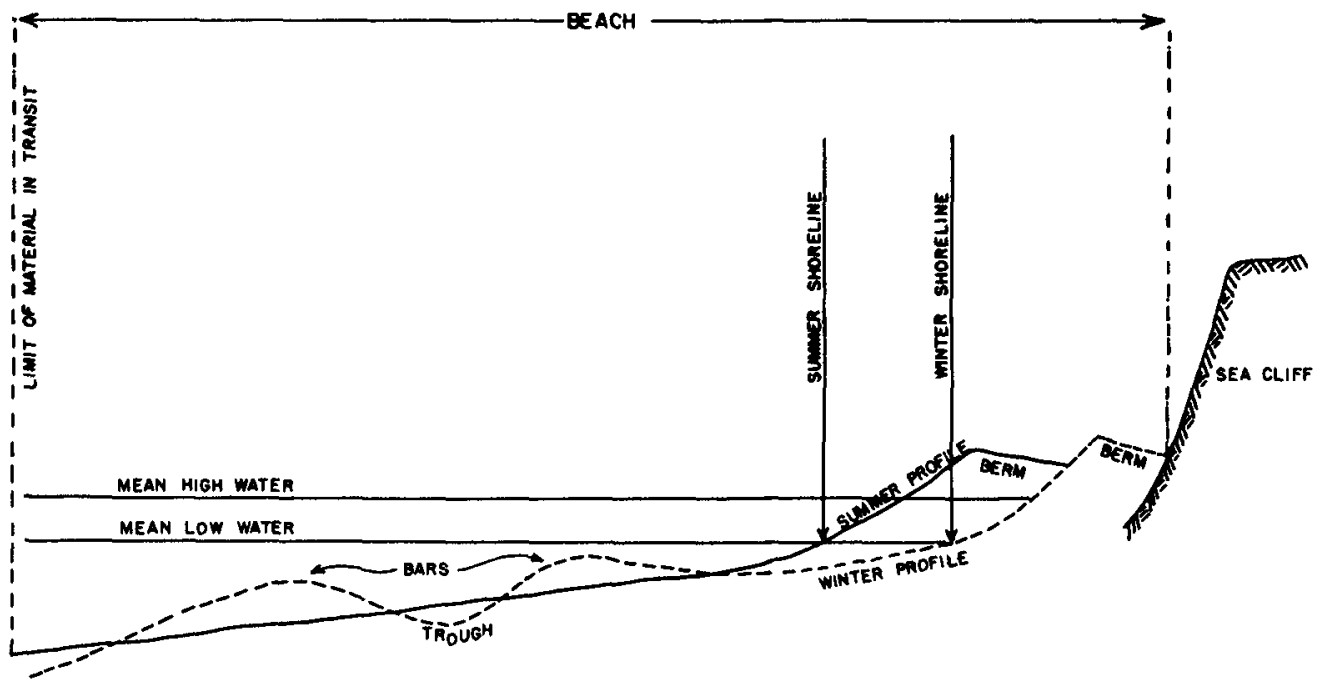

Fig. 1. Beach profile showing səasonal distribution of sand.

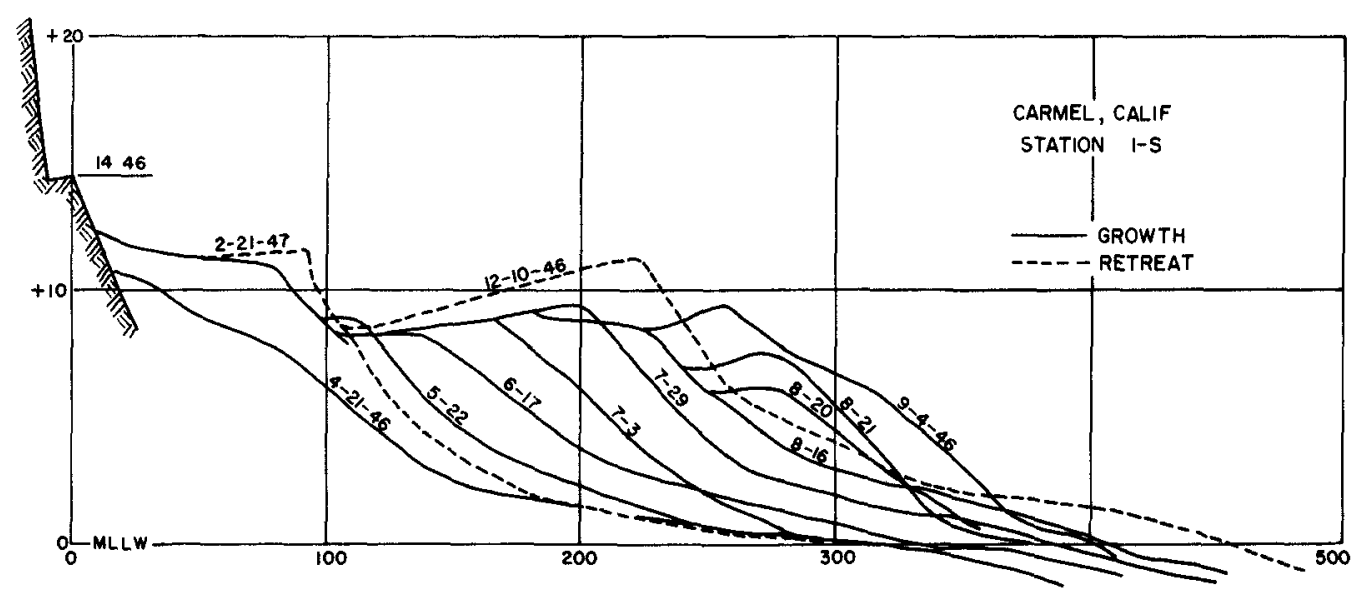

Fig. 2. Gowth and retreat of a berm. 


\section{CHARACTERISTICS OF NATURAL BEACHES}

berm and visa-versa. The most noticeable form that this transfer takes is the removal by storm waves of the part of the beach above water. The arrival of such waves after a quiescent period may move as much as 2,000 cubic yards overnight from a 100 yard length of berm.

What are the materials involved and how do the natural forces shift them? This paper will be restricted to the classical situation which probably represents over $90 \%$ of the beaches, and thus the problems, of the United States coasts. The forces are those of waves and wave-caused currents; the material is sand (dominantly quartz) with a median diameter of from 0.2 to $1.0 \mathrm{~mm}$.

There are other forces such as the winds which create local winddriven currents and act sub-aerially on the part of the beach above water, and there are other materials: fine sands, pebbles, shingle and boulders. (In fact the word beach originally meant the tabular-rounded sedimentary pebbles which so commonly compose the shorelines of the British Isles). For the sake of brevity, a detailed discussion of these comparatively minor forces and unusual materials will be omitted. It is important to note however, that the sandy beach forms which will be described are also seen, equally well developed, in pebbles and cobbles.

\section{BEACH FORMS}

"A beach is a deposit of material which is in transit either along shore or off-and-on shore". This dynamic concept of many particles in continual motion is attributable to G. K. Gilbert (1890) and D. W. Johnson (1919). Notice particularly that it includes particles seaward of the shoreline; the criteria is only that they be "in transit". It is so worded as to include longshore bars, troughs and rip channels which are quite as important to the student of beach processes as the above-water features.

Figure 1 makes use of stylized winter and summer profiles of the beach at Carmel, California to illustrate the more important features and indicate typical seasonal changes. Note that the volume of sand involved is a constant since the areas under winter and summer sections are about equal; the material merely shifts from berm to bar and back again.

Various major coastal features such as spits, offshore bars, baymouth bars and tombolos are composed of beach materials and, of course, have a present-day beach at their seaward edges. Such features are of greater interest to geologists than engineers and, since their overall rate of change is quite slow, will not be discussed here.

\section{LONGSHORE BARS}

Longshore or beach bars are ridges in the material of which the inshore bottom is composed and are usually thought of as being parallel to the shore and maintaining the same section for a considerable distance. 


\section{COASTAL ENGINEERING}

This ideal condition may exist if wave and current forces remain constant for a considerable time, however, a change in wave directzon will rapidly change neat lines of bars into a chaos of short irregular ridges with meandering troughs between. The origins of longshore bars have long been the subject of study and speculaticn and still there is no general agreement as to the detdils of the process by which they are formed and maintained. They form during storm conditions in which seaward flowing bottom currents remove material from the beach face and carry it seaward. The number of bars on a beach depends on the size of the waves, the general bottom slope and the tide range.

Consider a beach with an even sloping bottom (barless beach profile) which is subject to light wave action; sand is moved slowly ashore by the mechanisms discused later under Forces. A storm arises and the waves become much higher; more bottom is affected because the waves feel bottom sooner and sand continues to move towards shore from comparatively deep water. When these waves break and become translatory, the water moves forward with the wave form; its natural return is a seaward-flowing bottom current which transports sand eroded from the beach face. This seawardmoving sand meets the shoreward-moving sand under the line of breakers (where the transformation from oscillatory to translatory waves takes place); at this point the opposing currents neutralize each other and the sand deposits to form a bar. Once the process starts the effect is progressive. The rising mound of sand (the bar) causes more waves to break since it is shallower; it also concentrates the breakers of slightly varying height (which formerly broke at their respective depths) in one place. Waves are thus filtered by the bar; only those less than some critical height pass across without breaking - - when these reach some appropriate depth, they also oreak and an inner bar may be formed. When bar formation has progressed sufficiently, the bar projects well above the surrounding sand and the trough to its landward side is frequently wide and deep. This results in a further adjustment since broken waves are now progressing in deepening water rather than gradually shoaling water. The translatory waves created by breaking are sometimes able to reform into oscillatory waves and although a great deal of energy has been lost in the original breaking, the reformed wave may be as large as many of the smaller ones which passed over the bar without breaking; these waves break again on the inner bar. For this reason, practically all waves break on the inner bar with oreakers which are much smaller than those on the outer bar; for those waves which break twice, the difference in height between the two breakers is a measure of the amount of energy expended in the outer breaking. (Note that the height of a breaker is proportional to the square root of the energy).

Small waves are not able to obliterate the deep bars created by large storm waves since they do not affect the bottom sufficiently; however, as already mentioned, they do move sand ashore from shallow water and thus will tend to plane off bar tops and fill in troughs. This is abetted by the absence of scouring rip currents in light surf. The modification of 


\section{CHARACTERISTICS OF NATURAL BEACHES}

the inner bar anc the filling of the trough between it and the beach face occasionally results in a nearly flat surface intermediate between a bar and a berm which is called a low-tide terrace. As might be expected, these low-tide terraces are generally found on partly protected beaches or on exposed beaches which have experienced a long period of small waves. Thus, a large storm may create a deep bar which will remain largely unchanged through months of calmer weather (until another group of large waves exists to change it) although at the same time there may be considerable change in shallower bars and the beach inshore. This means that the depths of the several bars are not necessarily related except immediately after a large storm and that valid comparisons of bars and waves require continued observation of the beach before, during and after changes. In an attempt to discover the grosser mechanics of sand movement the Beach Erosion Board has conducted experiments with artificial bars at Long Branch, New Jersey and Santa Barbara, California which have given some negative information. In the hope of nourishing these sandstarved beaches, underwater sand ridges were placed in 38 and 18 feet of water respectively, the idea being that the wave action would bring the sand onto the beach. According to Hjulstom's formula for threshold velocity, the sand should have been moved by the waves that existed; however, the sand did not move appreciably and the mounds remained for a number of years. It should be noted, however, that no bars are known to exist even on those beaches of the United States Pacific Coast most exposed to violent storms which have crests more than 20 feet below mean lower low water. Figures obtained by averaging tabulated data from 29 surveys of exposed United States Pacific Coast beaches with two or more bars have turned up some interesting facts:

\section{Bar Depths}

$\begin{array}{llll}\text { Depth of inner bar } & - & 1.0 \mathrm{ft} . & \\ \text { Depth of second bar } & - & 7.5 \mathrm{ft} . & 6.5 \mathrm{ft} \text {. difference } \\ \text { Depth of third bar } & - & 13.0 \mathrm{ft} . & \end{array}$

Besch Slopes (measured between MLW and $-30 \mathrm{ft}$. or $3000 \mathrm{ft}$. off shore)

$\begin{array}{ll}\text { Less than } 1 / 75 & \text { three or more bars } \\ 1 / 75 \text { to } 1 / 50 & \text { two bars } \\ \text { Greater than } 1 / 50 & \text { one bar }\end{array}$

Note: All exposed beaches had at least one bar. No individual beach varied greatly.

The phrases "exposure" and "protection" are conveniently used to describe large differences in the amount of wave energy reaching a beach; it is to be expected that beach changes are of greater magnitude where violent waves occasionally impinge; the application of this to bars is of interest. 


\section{COASTAL ENGINEERING}

Like other beach features, bars have lower relief and are composed of smaller particles as protection is reached. Where protection is at a maximum as in the lee of a headland, bars rarely exist because waves never get steep enough to form them. Attempts to correlate bar spacing with wave length or other characteristics have been unsuccessful to date but there is a relationship between bar depth and wave height as already indicated. Thio cannot yet be stated quantitatively because of the large number of variables involved. Kuelegan (1945) compared bar depths with trough depths and decided that the depth of bars to the depth of troughs was a fairly constant relation; i.e. the depth of the trough divided by the depth of the bar (both measured from still water level) is approximately 1.69. Shepard (1950) measured additional profiles and found that the ratio was generally less ( 1.16 to 1.63$)$.

Since bars appear on tideless seas, obviously no tides are required for their formation; however, the previous statistics show that the difference in elevation between pairs of bars is nearly the same; this happens to be about the same as the tide range at those beaches. Water level is continuously changing because of the tide's surface but for about an hour before and after high and low tides, the water level is fairly constant. This means that there is considerable time for a bar to develop at a particular elevation during the high and low periods; in the transition period, the level changes too fast for the sand to follow. Because of this, the waves are able to form bars which are in use at both high and low tide; the outer bar at low tide will be the inner bar at high tide. At intermediate stages of the tide, unusually large waves will break three or more times, on each of the bars and the beach face. At lowest tide, the inner bar may be above water, or nearly so, and occasionally a ridge of sand appears on the seaward side of this bar wilich may be a vestigal remnant of a berm which started to form at extreme low tide. The tide range probably influences the number of tars that can exist since a large range would bring the wave action into contact with widely separated bottom areas. Steep oeaches exposed to the same wave action as flat ones have fewer bars because even at lower tides the rapidly deepening bottom is below the limit of wave action except on the flanks of the existing bars. The remarks about the depth of water in which waves influence the bottom must also be modified to take into account the usual rise in actual water level during a storm above that predicted. Although the average depth of the third bar is given as 13.0 feet below MLLW, the waves that cause that bar may be several feet more. Moreover, the slope of the bottom influences the depth of breaking and a bar obviously offers a steeper slope than the barless profile. These comments are based on information obtained by making detailed soundings of bars before, during and after heavy surf conditions on a variety of beach types.

Bars have been observed on beaches ranging in size, and subject to the wave action of, model tanks, lakes, seas and oceans. Vany types and sizes have been described; Hagen (1863) who first suggested their origin sam five on a single beach; Gilbert (1885) mentions bars on the shores of Lake 


\section{CHARACTERISTICS OF NATURAL BEACHES}

Vichigan* that could be traced for "hundreds of miles" (he probably did not mean that these bars were continuous, but even so, it is quite remarkable). Substantially unbroken bars 20 miles long have been seen on the Washington Coast (Isaacs, 1947). It should be pointed out though that it is hard for an observer ashore to say just what the length of a bar is, since bars are most easily judged by the breakers on them; breakers are highly variable in height along the crests and a large number of waves would have to be observed in order to say whether a low point was in the bar or in the waves.

BERUS

$A$ berm is a nearly horizontal formation of beach material brought ashore by the waves. Berms are, in a sense, the opposite of bars since they are the depositional sand form and bars are the erosional sand form; as described in detail elsewhere, the wave steepness appears to control which of the two will form. There is no general agreement as to the criteris for determining whether any beach has a berm, for on some beaches berms are difficult to recognize. If it is necessary to have a flat surface or a well-defined crest, many beaches will never have a recognizable berm. On the other hand, if the accretion of sand above water is to be the standard, obviously every beach must have a berm part of the time in order to exist above water. There appears to be no basic difference between the sand deposits that waves leave on very flat peaches (whlch are said by some to have no berms) and the sand deposits on intermediate slope beaches which have well-defined berms by any standard. On beach areas wnich have greater protection from wave action at one end than the other this is readily observed. On the most exposed portion, such a beach may have a definite berm with a rather ill-defined crest (coarse grained beaches rarely have clean-cut berms); on the part of the beach where the sand is intermediate in size and exposure is moderate, there will be'a sharp crest and a flat berm top; as the most protected area is approached, this berm fades into a fairly flat beach and is no longer discernable as a definite form. It will be noted that each of these areas falls within the definition and has a "nearly horizontal formation of beach material brought ashore by the waves" - - the point is that on the beach which is always "nearly horizontal" the berm is difficult to see.

Since berms are formed by wave action, height of the crest of the berm is a function of the height of the forming waves above the sea level at the time of formation. Experiments in a wave channel by Bagnold (1940) indicate that the height of the berm is $1.3 \times \mathrm{H}_{0}$ of the waves that formed it.

* The level of Lake Michigan varies as much as seven feet because of rainfall, evaporation, seiching and wind tides; these bars therefore are not necessarily related to the water level as observed. 
Although this research has not been extended sufficiently to determine a factor for ocean beaches as yet, the author's observations (Bascom 1953) indicate that such a relationship will eventually be shown in which some factor (possibly 1.3) multiplied by the refraction coefficient will give the height of the crest of the berm at any point. For this reason, the berm formed by any one set of waves is lower in protected areas than on exposed beaches. This effect has been observed at a numper of places including Monterey Bay, California where, on occasion, the crest of the berm is found to be 16 feet above MLWW on the exposed beach at Fort Ord, docreasing in the shelter of Point Pinos to 10 feet at Del konte Creek and becoming perhaps half of that in Monterey Harbor.

Berms are depositional features placed above water by wave uprushes. The action of the wave is something like this: Great turbulence exists in the surf zone, particularly at the line of breakers, which churns up the bottom sand and maintains it in suspension. After a wave breaks, the water rushes forward up the beach carrying the suspended sand, losing velocity as it goes because it is opposed by both gravity and friction, and at some point stops completely. When the velocity drops below the threshold of transport, the suspended material deposits. Since beaches are permeable, some of the water sinks down through the sand leaving a lesser amount to return along the surface as backrush. The water that does return on the surface must start from zero velocity; consequently a large part of the suspended sand which was carried up the beach remains near the termination of the uprush. The backrush reaches a high enough velocity to remove some sand from the lower part of the beach but the balance is in favor of deposition. The saturation of the beach face largely controls the relationship between the volumes of uprush and backrush water and it is readily seen that the short period waves keep the beach wetted best because the intervals between saturations are smaller. As already noted, the short period waves incraase the $\mathrm{H} / \mathrm{L}$ values which are the criteria for erosion or deposition. It may be reasoned then, that a most important erosional characteristic of waves is their ability to keep the beach wetted face saturated; by the same token, berms build more readily on "dry" beaches since there is less water returning along the surface to transport the sand seaward again.

As this process continues, the sand builds seaward; since the height of the waves above sea level controls the height of the berm crest, the tide has a considerable influence on berm height. If ocean waves were all of the same height, a rapidly growing berm surface might show undulationsin response to the tides. However, berms grow evenly vecause of the variation in the heights of waves and although the seaward growth results from the combined work of the average waves, the upward growth depends only on the largest waves. Where the berm crest is well developed, the uprushes of these largest waves pass completely over the crest and deposit the bulk of their sand load on the landward side. Since this can only 


\section{CHARACTERISTICS OF NATURAL BEACHES}

occur on the highest tides, the crest grows higher as it builds seaward and the shoreward side of the crest slopes inland. Thls has two effects on the growth of the berm.

(1) The water rushing shoreward down the gently sloping landward side levels off irregularities by depositing new sand and scouring off high points with the result that the berm may be quite flat.

(2) This water eventually saturates the beach completely and then stands in large puddles; eventually, when enough water gathers it is able to oreach the crest of the berm at the low point and flow back out to sea. Future uprushes crossing the crest deepen this cut and the result is a drainage channel, something like a "rip channel" in a bar, but forming on the upper beach.

This vertical growth of the berm caused by large waves creates an interesting paradox. Storm waves which eroce a beach also build a berm during the erosion. The uprushes of the large waves carry sand up and deposit it on top of the berm, adaing verticilly to its top even while the face is eroding so that when the storm condition subsides, a narrow but higher berm remains. Since large storms frequently occur in the winter when the beach is narrow, these higher berms are called winter berms and are found at the landward extremity of the beach. They will survive until subaerial erosion or a larger storm removes them. A prograding beach may have a series of abandoned berms at its landward side.

Since a berm is a depositional feature, its width is dependent on the sand supply and the length of time that waves exist which are capable of moving sand shorewerd. Because of the effects just described the most recent addition will frequently cover and obliterate traces of the previous berm limits. The examule of the growth of the Derm at Carmel Beach, California (Figure 2) illustrates this point. This particular berm disappears completely in the winter time and builds out as much as 300 feet by the end of summer.

The Growth and Retreat of a berm (Figure 2) (Vertical exaggeration 1:10) is worthy of additional explanation since it nicely demonstrates beach changes which are seldom so large or so well documented.

(1) The berm built gradually seaward at the rate of about forty feet a month during most of the summer when the light waves existed; in August and September the rate increased. No further surveys were made until December and February; by then the beach was found to have retreated almost to the cliff.

(2) The winter berm crests, formed as the beach retreated before high storm seas, were several feet higher than the summer berm crests. 


\section{COASTAL ENGINEERING}

(3) The growth of the berm from 20 August 1946 to 4 September 1946 was upward and outward partly because the height of high tide increased during that period (until the 26th) and partly because the waves were slightly higher.

(4) Each successive addition to the berm was higher so that the surface sloped landward to a run-off channel.

Newly formed additions to the berm usually have a rather soft surface compared to recently eroded surfaces of about the same slope; this softness is sometimes helpful in deciding whether the beach $1 \mathrm{~s}$ eroding or building. At Clatsop Plains, Oregon, a very flat beach where clear cut berm features rarely if ever exist, it was noticed one day that a DUKW traveled $20 \mathrm{mph}$ slower along the beach than it had at the same place on the previous day although no beach changes were evident visually. A survey showed that a foot of new sand had come ashore during the night.

\section{RIP AND RUN-OFF CURFLNTS}

Two transverse depressions that often dissect beaches are the rip channel and the run-off channel which cross the bar and the berm, respectively. These channels are cut by currents which perform parallel functions (one above water, one below) $i_{. e .,}$ the return seaward of water raised above average water level by wave action. Potential energy gained by this thin sheet of water raised along a length of beach is spent in eroding a narrow channel as it runs back to sea.

The actual amount of sand moved by these currents is secondary compared to their effect on the flow mechanism in the surf zone. In a sense they act as safety valves which drain off the excess head. The run-off channel behind the berm crest, for example, does not operate until the berm is completely saturated and water stands in a large puddle or lagoon. When the water surface has reached sufficient height to breach the lowest part of the berm, the lagoon water rushes out to sea reducing the head on the water percolating thru the beach. The rip channel and its feeders have a more serious effect on the inshore bottom. A bar must form much more rapidly if no rip current exists since all the water moved shoreward in translation must flow back out to the bar carrying sand with it. As soon as the rip forms, however, the returning water and suspended sand will flow seaward only as far as the trough where they will join the rip feeder current and move parallel to the shore until the rip itself is reached. The rip current flows seaward thru its channel in the bar (at velocities as much as four knots); outside the surf zone it slows down, breaks into eddies and drops its sand to form a delta. 


\title{
CHARACTERISTICS OF NATURAL BEACHES
}

\author{
NATURAI FOREIS
}

The offshore-onshore motion of sand which has just been discussed is more easjly observed and described than the longshore motion. This is because one can think of offshore-onshore motion as operating within a closed system, that is, the amount of sand involved is constant. Sand measurements plotted as profiles do not give information about the flow of sand across the profiles, they merely indicate the height of the "standing crop" and on a yearly basis the profile will show no net movement, Longshore sand movements are nearly always irreversable and therefore usualiy result in large net movements of sand from a length of coast which is eroding to a comparatively small place where deposition takes place (usually a sand spit). Such sand movements characterize coasts which make a large angle with the fronts of incompletely refracted swell approaching from the usual storm centers or which have local winds that blow steadily enough to maintain wind-waves with a constant direction. It is the coastwise momentum given to the inshore water by these waves striking the beach at an angle that drives the current which moves the sand. The development of means for dealing with this littoral movement caused by waves striking the beach at an angle is the principal coastal engineering problem today.

Longshore currents need not be of sufficient velocity themselves to pick up and transport sand, for in the surf zone the sand is put into suspension by the forces accompanyine wave transformation and very small currents are effective in moving the suspended material sidewise. Wave steepness, discussed in detail later, is an important factor in determining the rate of littoral drift. Higher waves effect the bottom deeper and keep the sand in suspension orer a wider area; shorter period vaves will be less refracted and strike the beach at a greater angle. The $v$ olume of material transported is therefore seen to be dependent on the height, period and attack angle of the waves as well as on the nature of the materials involved and the variations in the character of the zone of transport.

The paths of the materials in transport are of interest since the motion takes place on the beach as well as below water. Underwater the suspended materials sway back and forth in the wave orbits and presumably move in a roughly sinusoidal path at nearly the velocity of the littoral water current. On the beach face, particles oscillate with the uprush and backrush to create a figure which is best described as a series of skewed parabolas connected at their limbs.

Munch-Petersen (1939) has likened this littoral process to a conveyor belt the width of the surf zone whose belt speed is the current velocity. The accumulated deposit at the end of the belt may be very large. For example, Rockaway Spit at the entrance to New York Harbor grew at the rate of 200 feet per year for a long period (one mile in 23 years).

Man, in building shoreline structures that obstruct or influence littoral sand flows almost invariably creates a dual problem: (1) sand will 


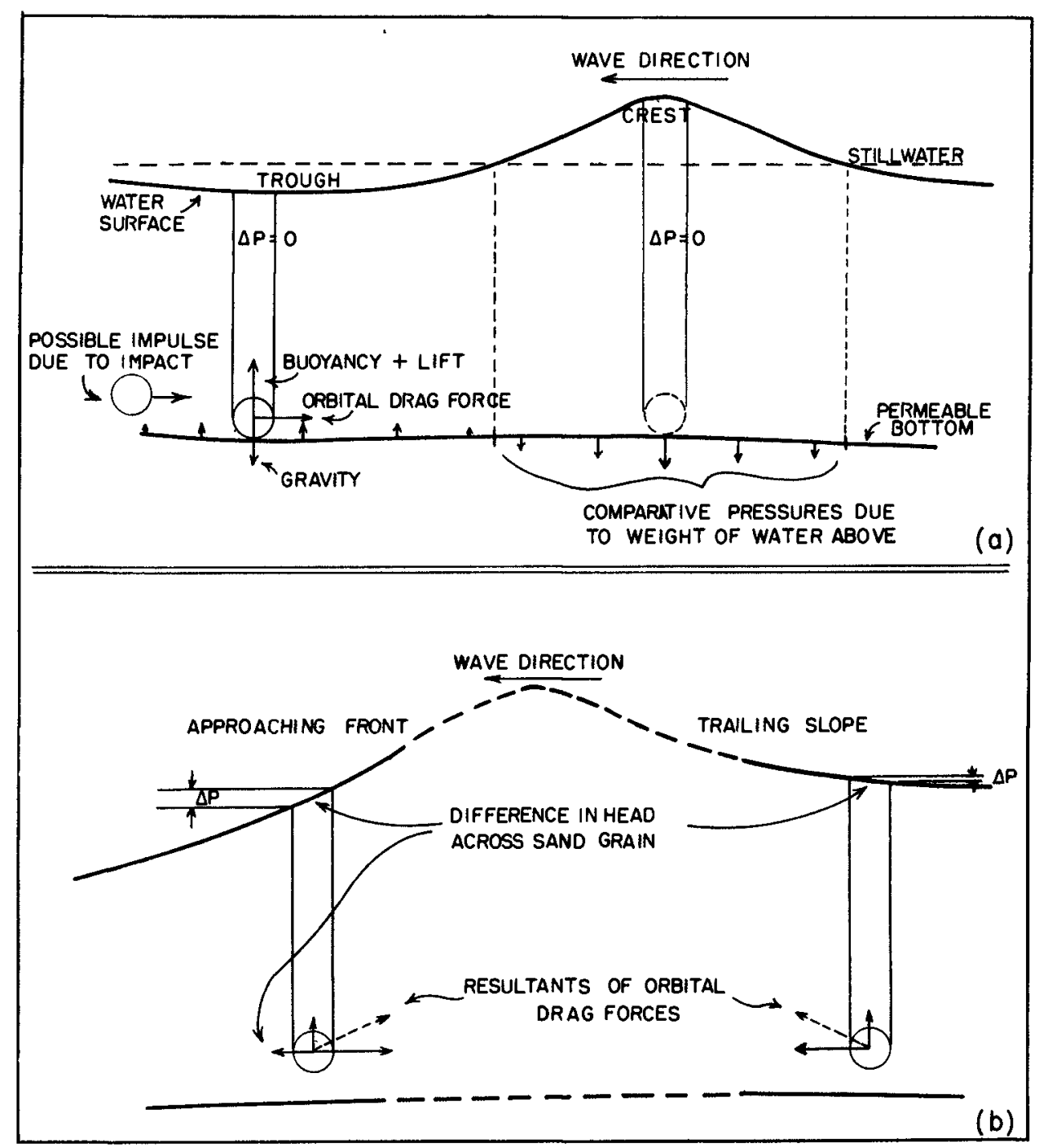

Fig. 3. Forces on a sand particle. 


\section{CHARACTERISTICS OF NATURAL BEACHES}

deposit wherever comparatively quiet water is created and (2) cut of the supply of sand to beaches downstream from the structure which will retreat.

\section{FORSES ON A SAND PARTIGLE}

A description of the characteristics of beaches is made difficult by their constant change and although it is an easy matter to define or describe the sand forms, it is not yet possible to say exactly which forces cause the shifting or how. In spite of the great mass of wave records, surf observations, and detailed beach surveys obtained in the last few years the level of knowledge is not much above that which has existed for a hundred years: "storm" waves move sand from berm to bar; "calm" seas move it back。

Since the means by which the individual sand grains are moved about is the heart of the problem it is perhaps worthwhile to examine the forces in some detail.

Consider the complex environment of a single grain of sand on the surface of the inshore bottom subject to the action of almost-breaking waves. (See Figure 3 ). Although it is helf down by gravity it is buoyed up by the medium it displaces (a slurry of sand and water with a density greater than that of water) and consequently the net dowmward force is comparatively small. A wave approaches. As the trough passes the pressure on the sand grain is relaxed, because of the decrease in head, while at the same time the bottom under the crest is subjected to additional pressure. Consequently there is flow through the bottom depending on its permeability and water will emerge under the wave trough and tend to lift the particle. This flow, when it exists, is reflected in the next-to-bottom orbits. Immediately above an impervious bottom these orbits will parallel the bottom; above a permeable bottom through which there is flow the orbit will be warped and take on a vertical dimension. At the same time trag forces rosulting from the orbital current acts to move the grain seaward and lift forces (due to the particle's convex upper surface) tend to raise it. Velocity is now at a maximum, acceleration a minimum, and the water surface above the grain nearly horizontal. This grain, on the bottom may also receive an impulse by being struck by other grains slightly above the bottom and moving with higher velocity.

A fer seconds later the steep face of the approaching wave is directly over the grain which is now slightly above the bottom. At this time there is differential pressure on opposite sides of the sand grain due to the slope of the water surface above; this will have a tendency to move it landward with the wave form. The horizontal seaward velocity has now diminished and a rertical component of orbital force influences the particle to move upward.

As the crest passes, upward velocity of the orbital currents is a 


\section{COASTAL ENGINEERING}

maximum as is pressure on the bottom; here again no pressure gradient due to surface slope exists. Horiznntal acceleration is at a maximum ss the velocity goes to zero and then reverses direction.

The trailing slope of the wave crest, less steep than its front, creates a roverse but somewhat smaller pressure gralient across the sand grain; at this time high orbital velocities landward and slightly upward are attained.

As the cycle is completed the orbit of the water particles starts downward again; its velocity (and consequently its available drag force) is reduced and the sand grain is returned to the bottom. Does it return to its point of beginnine each cyole?

A.Iditional complexities are caused by waves (often sevgral trains arrivine at once), which are highly variable in height and period and strike the beach at various angles. The roughness and slope of the bottom, the size, shape, and weight of the particle and the depth each has a certain effect on the flow and the intensity of wave forces on the bottom.

The problem is to decide whether the sant grain sustained any net movement or not and in which direction.

It is evident from the changes in the beach forms that the net force must change, causin 3 and to migrate; however as yet one cannot say definitely which combination of these minute forces is dominant at any given time. Certain Eeneralizations are possible about the relative magnitude of forces and the chances of their ascendency.

Most important is the fact that objects immersed in water tend to do what the water around them does --- especially particles whose resistance is high compared with the net downward iorce (low settling velocity). Thus, a grain of sand churned into suspension by the highest breakers of a group of waves will often settle slowly enough to partake of the orbits (and the mass transport) of small succeeding waves. In addition the particle will be subject to any alongshore motion which the water mass may have as it is driven by wind or by translatory waves moving at an angle with the shore.

Waves which are actually breaking must be of considerable importance in moving sand grains; here again one is limited to qualitative descriptions. Two events associated with breaking are readily recognizable as being influential. The first of these is the effect of plunging breakers in sending a jet of water down to the bottom through the preceeding trough; that is, the water mass flung forward by the plunge maintalns enough integrity to reach the bottom and chum up sand (a motion readily observed by swimmers).

The other effect of breaking is the change from the orbital state where comparatively little forward motion (mass transport) takes place, to 


\section{CHARACTERISTICS OF NATURAL BEACHES}

translatory motion in wich the water moves forward with the wave form. The water in translation moves rapidly and turbulently and carries with it whatever items may be in suspension. Since the waves which mun up the beach face are almost always translatory, this pmbably accounts for most of the actual motion of sand upwards onts the berm.

\section{WAVE STEEPNESS}

There is $\mathbf{s}$ ome evidence that sand always moves in the same direction as the wave form unless the usual driving force is overridden by some temporarily stronger force in the opposite direction but no critical experiments in actual wave conditions have yet proven this point. As previously discussed, this usual driving force is probably attributable to either a mass transport effect or to the differential pressures due to the slope of the water surface. The opposing forces, whatever they may be, are obviously dominant at the time of storm waves (usually defined by their steepness, $\mathrm{H}_{\mathrm{O}} / \mathrm{I}_{\mathrm{O}}$ ). According to Johnson (1949), model tank experiments show that a wave steepness of greater than 0.03 will always cause a bar to form and a steepness of less than 0.025 will never cause ont to form. The validity of these numbers at any actual beach is somewhat doubtful but the trend seems quite clear. It seems unlikely that the steepness itself is effective in reversing the sand $\mathrm{flow}$; more probably some other characteristic acting at the same time is responsible.

The meaning of wave steepness is deserving of discussion since it is generally considered to be an important criterla in determining the direction of transfer of beach materials. Steepness $\left(H_{0} / L_{0}\right)$ is the ratio of the deep water height to the square of the period $\left(T^{2}\right)$ times a constant $(8 / 2 \pi)$ (shallow water-steepness is proportional). Therefore the steepness can incroase either with an increase in height or a decrease in period. A greater steepness means a greater slope on the wave front and consequently a greater pressure gradient between troikg and crest and a greater driving force on the water in the orbit. This cradient, as previously indicated, must be inc reasingly effective in (I) causing flow through the bottom and (2) in exerting differential pressure on the individual sand grains (in both directions but with a net force landward). Another result of steepness is the rate of delivery of water to the beach as indicated by a decrease in $T$. Short period waves allow little time for settling between waves and consequently a greater amount of material is maintained in suspension.

An even more important effect of steepness is the comparative unstableness of the crest which makes it more likely to break. The greater percentage of breakers results in a greater transport of water to the beach by translatory motion which results in the raising of a "he ad" of water in the nearshore zone. Since the rate of delivery of water to this area is high, the surf zone rater level actually slopes upward to the shoreline; 


\section{COASTAL ENGINEERING}

this water naturally seeks to return seaward and there are two paths by which it travels. It either flows transversely outward through or along the bottom, or it moves parallel to the beach in the innermost trough (as a feeder current) until it reaches a rip channel wherce it flows to sea through a breach in the bar. Both of these currents must be responsible for sand movement but only in the case of the rip current (which sometimes makes a delta) is it readily observed.

On the beach face the importance of wave steepness is related to the permeability of the sand. Think of a single uprush moving up a dry beach face; it is a small translatory wave and carries sand grains with it. As it goes some of the water sinks through the sand and percolates down to join the water-table. At the maximum extent of the uprush, little water is left and consequently there is no transporting medium to move the sand grains back down the beach face. The water that does return along the beach face must start from zero velocity (below the threshold of sand transport) and consequently a large part of the suspended sand which was carried upward remains near the termination of the uprush. If the rate of delivery of water and sand is slow (small steepness), there is time for this percolation to take place and each uprush adds to the sand on the beach. If the steepness is large, the rapid succession of waves maintains a saturated beach and the upmusn water returns down the beach face carrying much of its load with it and scouring additional sand from the lower face as it goes.

\section{SUMMARY}

In summary, beaches may be said to have the following principal characteristics:

1. They are composed of constantly shifting groups of particles which move and orient themselves to fit changing waves and currents.

2. These particles make up the two major beach forms the berm (abovo water) and the bar (below water). The transfer of material between the two seems to be dependent on the wave steepness.

3. The relief of these features and the slope of the beach face is related primarily to the particle size but also to the character of the waves which formed it.

4. Sand will move in the same direction as the wave form except when some local condition, such as a bottom current flowing in the opposite direction, becomes predominant.

5. Where the dominant wave systom strikes the beach at an angle, 


\title{
CHARACTERISTICS OF NATURAL BEACHES
}

\begin{abstract}
a littoral current is set up that maintains an irreversable flow of $s$ and along the coast. This sand will deposit when it reaches comparatively quiescent water--thus causing serious coastal enginaerinğ problams.
\end{abstract}

The great number of small forces which act in various ways on the sand grains make the study of beach dynamics a complex one and the lack of definite quantitative information at the present time about the causes of sand migration make a paper such as this a mere "state of the art" discussjon. It is hoped that engineers and observers vill be challenged sufficiently by the indicated missing pieces of irformation to levise critical field experiments that will end speculation about these unscalable phenomena. The answers must be sought in the natural environment where the engineer must work; persistent effort will some day give ma control over the beach envi ronment.

\section{REFERENCLS}

Bagnold, R. A. (1940). Beach Formation by Waves; Some Model Experiments in a Wave Tank: Journal of the Institution of Civil Engineers No. 1, Paper No. 5237, pp. 27-52.

Bascom, W. N. (1947). Field Studies at Monterey (twp parts): Institute of Engineering Research, Iniversity of California, Roport No. HE 116-224.

Bascom, W. N. (1951). Investigation of Sand Movements at Santa Barbara Harbor: Institute of Engineering Research, University of California, Series 14 , Issue 8.

Bascom, W. N. (1951). Relatiorship Between Sand Size and Beach-face Slope: Transactions of A. G. U. Vol. 32 No. 6 .

Bescom, W. N. (in press). Control of Stream Outlets by Wave Refraction: Journal of Geology.

Bascom, W. N. (1951). Shoreline and Beach Characteristics: Manual of Amphibious Oceanography, Office of Naval Research.

Gilbert, G. K. (1890). Topographic Features of Lake Shores: 5 th Annual Rep., 1885, U. S. Geol. Survey, Monograph I, Lake Bonneville.

Hagen, C. (1863). Handbuch der Wassarbaukunst: 3 Teil, Das Mer I, Berlin.

Hjulstrom, Filip. Transportation of Detrius by Moving Water: Recent Marine Sediments, A. A. P. G.

Isaacs, J. D. (1947). Beach and Surf Condition on Oregon-Washington Coast: Institute of Engineering Besearch, University of California, Report No. HE $116-229$.

Johnson, D. W. (1919). Shore Processes and Shoreline Development: New York, John Wiley and Sons. 


\section{COASTAL ENGINEERING}

Johnson, J. W. (1949). Scale effects in Hydraulic Models Involving Wave Motion: Transactions American Geophysical Union, Vol. 30, pp. 517-525.

Kuelegan, G. H. (1945). Depths of Offshore Bars: Engineering Notes No. 28, Beach Erosion Board, Military Intelligence Division, U. S. Army.

Munch-Peterson (1938). Littoral Drift Formula: Bulletin, Beach birosion Board, Vol. 4, No. 4 (1950)

Shepard, F. P. (1950). Longshore Bars and Iongshore Troughs: Tech. Memo. No. 15, Beach Erosion Board, Corps of Engineers.

Shepard, F. P., Emery, K. O., and LaFond (19/4l). Fip Gurrents: A Process of Geological Importance: Journal of Geology. 